\title{
Omega-3 fatty acids and FFAR4
}

\section{Da Young Oh* and Evelyn Walenta}

Division of Endocrinology and Metabolism, Department of Medicine, University of California San Diego, La Jolla, CA, USA

\section{Edited by:}

Ikuo Kimura, Tokyo University of Agriculture and Technology, Japan

Reviewed by:

Undurti Narasimha Das, UND Life Sciences, USA

Helena Barbosa Sampaio, State University of Campinas, Brazil

\section{*Correspondence:}

Da Young Oh, Division of

Endocrinology and Metabolism, Department of Medicine, University of California San Diego, 9500 Gilman Drive, La Jolla, CA 92093, USA e-mail: dayoungoh@ucsd.edu

\begin{abstract}
The beneficial roles of omega-3 fatty acids ( $\omega 3-\mathrm{FAs}$ ) on obesity, type 2 diabetes, and other metabolic diseases are well known. Most of these effects can be explained by their antiinflammatory effects triggered through their receptor, free fatty acid receptor 4 (FFAR4) activation. Although the whole mechanism of action is not fully described yet, it has been shown that stimulation of $\omega 3$-FA to FFAR4 is followed by receptor phosphorylation. This makes FFAR4 to be capable of interacting with $\beta$-arrestin- 2 , which in turn, results in association of $\beta$-arrestin- 2 with TAB1. This stealing of an important partaker of the inflammatory cascade leads to interruption of the pathway, resulting in reduced inflammation. Besides this regulation of the anti-inflammatory response, FFAR4 signaling also has been shown to regulate glucose homeostasis, adiposity, gastrointestinal peptide secretion, and taste preference. In this review, we summarize the current knowledge about the interaction of $\omega 3$-FAs with FFAR4 and the consequent opportunities for the application of $\omega 3$-FAs and possible FFAR4 targets.
\end{abstract}

Keywords: omega-3 fatty acids, FFAR4, anti-inflammation, insulin resistance, obesity

\section{INTRODUCTION}

Free fatty acids (FFAs) serve both as a source of energy and as signaling molecules that regulate energy homeostasis and other physiological processes $(1,2)$. Previous studies proposed that lipotoxic stress from long-chain saturated FFAs is a major cause of JNK activation and therefore insulin resistance in obesity $(3,4)$. It has also been reported that long-chain saturated FFAs, but not polyunsaturated FFAs, induce inflammatory responses in macrophages (5). Among polyunsaturated FFAs, omega-3 fatty acids ( $\omega 3$-FAs) have been recognized for their beneficial effects on human health (6). These beneficial effects were found in inflammatory diseases, cardiovascular diseases, and hepatic lipid metabolism, as well as glucose homeostasis and insulin sensitivity $(7-10)$. However, the detailed mechanisms underlying the beneficial effects of $\omega 3$-FAs have not been completely defined to date.

It is known that the $\omega 3$-FAs, such as $\alpha$-linolenic acid $(\alpha-$ LA), docosahexaenoic acid (DHA), and eicosapentaeonic acid (EPA) are endogenous ligands for the free fatty acid receptor 4 (FFAR4) (11-13). FFAR4, also known as G protein-coupled receptor 120 (GPR120), is a seven transmembrane receptor and was first reported as an orphan GPCR in 2003 (14). FFAR4 exists as two splice variants in humans $(15,16)$, but only the shorter variant has been found in rodents and cynomolgus monkeys (17). Consistent with the pleiotropic effects of $\omega 3$-FAs, FFAR4 has been implicated in diverse processes including anti-inflammation, insulin sensitization, release of gut peptides, and alteration of food preference $(12,13,18-21)$. The wide range of processes that can be positively influenced by FFAR4 makes this receptor of potential importance in the prevention and treatment of metabolic diseases.

\section{MECHANISIMS}

Consistent with roles in diverse processes, FFAR4 is expressed ubiquitously including lungs, colon, small intestine, brain, thymus, adipose tissue, taste buds, skeletal muscle, heart, and liver
$(12,18,21,22)$. However, the expression pattern differs between species and also depends on the method of detection (23). Furthermore, the expression in skeletal muscle, heart, and adipose tissue is upregulated by a high fat diet (HFD) $(18,19,22)$. Despite the variation of expression, FFAR4 seems to transduce $\omega 3$-FA signaling always through one of two pathways that involve either $\mathrm{G}_{\alpha \mathrm{q}}$ or $\beta$-arrestin-2 $(12,13)$ (Figure 1). FFAR4 coupling to $G_{\alpha q}$ induces a rise in intracellular $\mathrm{Ca}^{2+}(12,21)$ without affecting the level of cyclic AMP (12). Alternatively, FFAR4 can respond to $\omega 3$-FAs by recruiting cytosolic $\beta$-arrestin- 2 to the plasma membrane, leading to internalization of the FFAR4/ $\beta$-arrestin-2 complex (13). After internalization, $\beta$-arrestin- 2 then directly associates with TGF- $\beta$ activated kinase 1 (TAK1) binding protein (TAB1), which is an adaptor molecule for the pro-inflammatory kinase TAK1 (24). In this way, $\beta$-arrestin- 2 sequesters TAB1 from TAK1, leading to inactivation of TAK 1 and abrogation of signaling to the inflammatory key-players IKK $\beta / \mathrm{NFKB}$ and MKK4/JNK/AP1 (13). Besides blocking the inflammatory pathway via the TAB1/TAK1 complex, FFAR4 activation by DHA also stimulates cytosolic phospholipase $\mathrm{A}_{2}\left(\mathrm{CPLA}_{2}\right)$ and prostaglandin-endoperoxide synthase 2 , also known as COX-2 (25). This leads to increased production of prostaglandin $\mathrm{E}_{2}\left(\mathrm{PGE}_{2}\right)$, which in turn, inhibits $\mathrm{NF \kappa B}$ signaling through the prostaglandin $\mathrm{E}$ receptor 4 and therefore reduces inflammation in macrophages as well (25).

After activation by ligands, GPCRs are phosphorylated to provide binding opportunities for certain $G$ proteins and arrestins (26, 27). Investigating the human short isoform of FFAR4, SánchezReyes et al. (28) found that DHA and $\alpha$-LA induce phosphorylation of FFAR4 by protein kinase C (PKC), leading to increase of intracellular $\mathrm{Ca}^{2+}$ concentration. However, recent studies of the long isoform of FFAR4 by Burns et al. (29) showed that basal as well as heterologous FFAR4 phosphorylation is mediated by PKC, while DHA-induced phosphorylation is accomplished by GPCR kinase 6 (GRK6). Interestingly, mutation of the FFAR4 C-terminal 


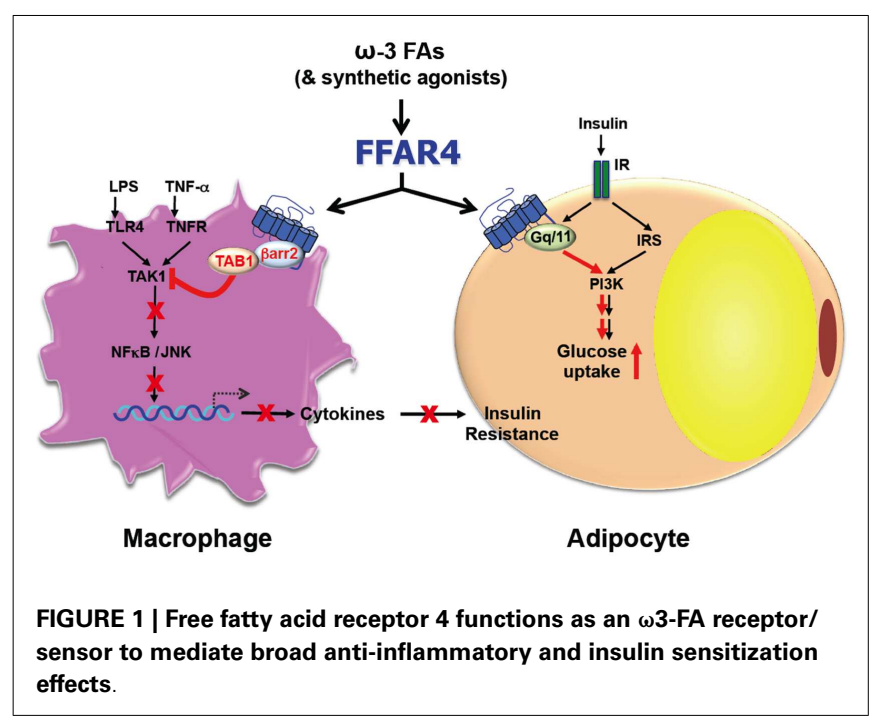

phosphorylation sites leads to enhanced $G_{\alpha q / 11}$ signaling while impairing $\beta$-arrestin- 2 recruitment to the cell membrane. However, Burns et al. (15) also found that the human short and long isoforms differ in their basal levels of phosphorylation, raising the possibility that the short isoform is more constitutively active. In the activated state though, both isoforms show comparable extent of phosphorylation. While the long isoform is proposed by Watson et al. to bind with greater affinity to $\beta$-arrestin-2 (16), a partial loss of function is proposed for the long isoform by Hirasawa et al. (12) and Moore et al. (17).

\section{TISSUE-SPECIFIC FUNCTIONS}

Due to the divergence of the reported functions, FFAR4 shows tissue-specific activities, which needs to be taken into account particularly for the development of pharmaceutical intervention. Therefore, a tissue-specific knockout (KO) mouse would be of high interest to discover precisely where certain effects of FFAR4 impact. This is critical for the development of agents that target inflammation, insulin resistance, and as a result, type 2 diabetes. However, no conditional FFAR4 KO mouse is available to date and mouse models cannot be used to investigate the function of the long isoform of FFAR4, which is unique to humans. Given the known differential phosphorylation of the two isoforms (15), their functions and regulation likely differ, which will have to be addressed in human tissues and cell lines.

\section{ADIPOGENESIS}

Free fatty acid receptor 4 expression is undetectable in preadipocytes $(18,30)$ but increases during adipogenic differentiation $(18,30)$, and becomes highly abundant in mature adipocytes and adipose tissue $(13,18,19)$. The expression in adipose tissue is further increased by diet-induced obesity in mice and humans $(18,19)$. Conversely, knockdown of FFAR4 using siRNA reduces the expression of adipogenic markers and therefore impairs the accumulation of lipids in 3T3-L1 adipocytes (18). Although these findings suggest a pro-adipogenic function of FFAR4, FFAR4deficient mice are actually more prone to diet-induced obesity than wild type littermates (19), consistent with an anti-obesity function of FFAR4.

It should be mentioned that discordant phenotypes of FFAR4 $\mathrm{KO}$ mice have been reported using two different mouse models. Thus, the body weight of FFAR4 KO mice is either increased (19) or unaffected (31) on HFD, and the insulin sensitivity is either decreased (31) or unaffected (19) on chow diet between wild type and $\mathrm{KO}$ mice $(13,32)$. Being all on the same C57BL/6 background, the mice seem to be either the $\mathrm{N}$ or the sub-lines, which might explain the varying findings. However, all models consistently establish the key site of FFAR4 action to be the adipose tissue, where $\omega 3$-FAs clearly exert FFAR4-dependent anti-diabetic effects in adipocytes and macrophages $(13,18,19)$.

\section{INFLAMMATION}

Omega-3 FAs have tissue-specific as well as systemic antiinflammatory effects (33). FFAR4 is key to these benefits in adipose tissue macrophages, which abundantly express this receptor. Furthermore, FFAR4 expression in macrophages is induced upon obesity. It was shown that its activation by $\omega 3$-FAs in mice fed with HFD supplemented with $\omega 3$-FAs leads to the suppression of macrophage infiltration into adipose tissue (13). Additionally, w3-FAs shift the distribution of macrophages in favor of the anti-inflammatory M2 macrophages at the expense of the pro-inflammatory M1 macrophages (13). In the brain, intracerebroventricularly injection of either $\omega 3$ - or $\omega 9$-FAs induces FFAR4/ $\beta$-arrestin- 2 coupling followed by the release of TAK1 from TAB1, leading to attenuation of the inflammatory pathway (34). Additionally, Wellhauser et al. showed the anti-inflammatory effects of FFAR4 activation in immortalized hypothalamic neurons (35). This is of importance as on HFD that hypothalamus becomes inflamed and fails to regulate energy homeostasis through regulating glucose handling, feeding, and therefore, body weight.

Finally, FFAR4 activation also leads to improvement of nonalcoholic fatty liver disease (NAFLD) in children (36). In more detail, Nobili et al. detected FFAR4 expression in hepatocytes, liver macrophages, and liver progenitor cells. DHA treatment of children suffering from NAFLD increased the FFAR4 expression in hepatocytes and reduced nuclear NFкB translocation in hepatocytes and liver macrophages, as well as reduced hepatic progenitor cell activation and the number of inflamed macrophages in the liver (36). Accordingly, w3-FAs also protect liver from ischemic reperfusion injury (IRI), a complication of liver surgery. Treatment with Omegaven ${ }^{\circledR}$, a pharmaceutical $\omega 3$ formulation, reduces $\mathrm{NF} \mathrm{B}$ and JNK response and shifts the macrophage population from M1 to M2 (37).

\section{INSULIN SIGNALING}

Besides the food intake and digestive influences of FFAR4 activation by $\omega 3$-FAs, increased gut glucagon-like peptide 1 (GLP1) secretion increases pancreatic insulin secretion, leading to enhanced glucose uptake in skeletal and cardiac muscle $(38,39)$. Whether FFAR4/ $\omega 3$-FAs play a cell-autonomous role in muscle, the major site of insulin-stimulated glucose uptake and systemic insulin action $(40,41)$, has yet to be investigated in detail, as Cornall et al. (22) found FFAR4 expression increased in skeletal 
and cardiac muscle of rats on HFD, while no expression was detected in L6 myocytes (13). Nevertheless, it has been shown that FFAR4 activation by $\omega 3$-FAs leads to insulin sensitization in vivo and also alleviates glucose intolerance in diet-induced obese mice $(13,19)$. Although the anti-inflammatory effects of $\omega 3$-FAs require FFAR4 coupling to $\beta$-arrestin-2, the hypoglycemic effect of insulin requires $G_{\alpha q}$ signaling that leads to translocation of the glucose transporter GLUT4 (13). Conversely, FFAR4 KO mice show reduced phosphorylation of IR $\beta$ and IRS- 1 in white adipose tissue and of IRS- 1 and -2 in liver, which are all important regulators for glucose uptake (19). Not surprisingly, these mice develop hyperglycemia, glucose intolerance, and insulin resistance when challenged with a HFD (19).

\section{GASTROINTESTINAL REGULATION}

Gastrointestinal peptides are known to regulate food intake, energy metabolism, and body weight (42-47). Activation of FFAR4 by $\omega 3$-FAs has been shown to either reduce or induce the secretion of several gastrointestinal peptides. For example, FFAR4 activation decreases the secretion of ghrelin, an endogenous growth hormone secretagogue that stimulates hunger $(48,49)$. Additionally, FFAR4 was shown to induce the secretion of GLP-1 and cholecystokinin (CCK) $(12,20,21)$. GLP-1 is an insulinotropic, anorectic peptide that reduces gastric emptying and motility $(43,44)$. CCK is similar to GLP-1 in that it inhibits gastric motility, but in addition it inhibits gastric secretion while promoting pancreatic secretion and gallbladder contraction (50). It was shown by Stone et al. that FFAR4 activation leads to decreased somatostatin secretion (51), which in turn, can increase insulin and glucagon secretion as well as gastric emptying. This is in sharp contrast to the recent finding by Suckow et al. of increased glucagon secretion in FFAR4 KO mice (32).

Unfortunately, some of these findings are contradictory. Although several groups demonstrated FFAR4 expression in islets (52-54), there is no consensus on the site of action, like influencing secretion of GLP-1, glucagon, or somatostatin, and even the cell type in which it is expressed most, is contradictory $(21,32,51)$.

\section{TASTE PREFERENCES}

Free fatty acid receptor 4 is abundantly expressed in several types of taste bud cells (55-57) and therefore can be activated directly by dietary $\omega 3$-FAs. Although detailed investigation is needed, it seems that FFAR4 might dictate spontaneous preference for specific dietary fats (31) that are abundant in energy-dense foods (58). However, Ozdener et al. (57) found that CD36 is the primary receptor for fat taste, while FFAR4 senses excess supply of FAs as in HFD.

\section{SYNTHETIC LIGANDS OF FFAR4}

Like FFAR4, FFAR1 (a.k.a. GPR40) is a receptor for long-chain $\omega 3$-FAs. Although the two receptors share endogenous as well as several synthetic agonists (11), like the PPAR $\gamma$ derivate GW9508 $(59,60)$, a few ligands are known to be partly or more selective for FFAR4 than FFAR1, namely grifolic acid, NCG21, GSK137647A, and TUG-891 (61-64). However, the relatively low efficacy of these known synthetic agonists in several measured outputs raises questions whether these can be therapeutically relevant molecules.

\section{PERSPECTIVE}

Solving the mechanism of FFAR4/w3-FAs might lead to a more directed and therefore more potent way of fish oil supplementation. But besides that, the understanding of the mechanism hopefully will lead to the development of a more FFAR4-specific, high affinity agonist. The direct activation of FFAR4 itself is of special interest, as FFAR4 is a "druggable" GPCR. Unfortunately, to date, there are no FFAR4-specific agonists that spare other GPCRs like FFAR1, which leads to off-target effects. It might be possible to develop an FFAR4 agonist that is tissue, pathway-, or isoform-specific and therefore provides antiinflammatory/insulin-sensitizing effects. Taken together, finding of an FFAR4-specific agonist will be a new therapeutic approach for the treatment of both metabolic and inflammatory diseases.

\section{REFERENCES}

1. Chawla A, Repa JJ, Evans RM, Mangelsdorf DJ. Nuclear receptors and lipid physiology: opening the X-files. Science (2001) 294(5548):1866-70. doi:10.1126/ science.294.5548.1866

2. Duplus E, Forest C. Is there a single mechanism for fatty acid regulation of gene transcription? Biochem Pharmacol (2002) 64(5-6):893-901. doi:10.1016/ S0006-2952(02)01157-7

3. Nguyen MT, Satoh H, Favelyukis S, Babendure JL, Imamura T, Sbodio JI, et al. JNK and tumor necrosis factor-alpha mediate free fatty acid-induced insulin resistance in 3T3-L1 adipocytes. J Biol Chem (2005) 280(42):35361-71. doi:10.1074/jbc.M504611200

4. Solinas G, Naugler W, Galimi F, Lee MS, Karin M. Saturated fatty acids inhibit induction of insulin gene transcription by JNK-mediated phosphorylation of insulin-receptor substrates. Proc Natl Acad Sci U S A (2006) 103(44):16454-9. doi:10.1073/pnas.0607626103

5. Shi H, Kokoeva MV, Inouye K, Tzameli I, Yin H, Flier JS. TLR4 links innate immunity and fatty acid-induced insulin resistance. J Clin Invest (2006) 116(11):3015-25. doi:10.1172/JCI28898

6. Kantha SS. Dietary effects of fish oils on human health: a review of recent studies. Yale J Biol Med (1987) 60(1):37-44.

7. Serhan CN, Chiang N, Van Dyke TE. Resolving inflammation: dual antiinflammatory and pro-resolution lipid mediators. Nat Rev Immunol (2008) 8(5):349-61. doi:10.1038/nri2294

8. Lee JH, O'Keefe JH, Lavie CJ, Harris WS. Omega-3 fatty acids: cardiovascular benefits, sources and sustainability. Nat Rev Cardiol (2009) 6(12):753-8. doi:10.1038/nrcardio.2009.188

9. Scorletti E, Byrne CD. Omega-3 fatty acids, hepatic lipid metabolism, and nonalcoholic fatty liver disease. Annu Rev Nutr (2013) 33:231-48. doi:10.1146/ annurev-nutr-071812-161230

10. Flachs P, Rossmeisl M, Kopecky J. The effect of n-3 fatty acids on glucose homeostasis and insulin sensitivity. Physiol Res (2014) 63(Suppl 1):S93-118.

11. Yonezawa T, Kurata R, Yoshida K, Murayama MA, Cui X, Hasegawa A. Free fatty acids-sensing $\mathrm{G}$ protein-coupled receptors in drug targeting and therapeutics. Curr Med Chem (2013) 20(31):3855-71. doi:10.2174/09298673113209990168

12. Hirasawa A, Tsumaya K, Awaji T, Katsuma S, Adachi T, Yamada M, et al. Free fatty acids regulate gut incretin glucagon-like peptide-1 secretion through GPR120. Nat Med (2005) 11(1):90-4. doi:10.1038/nm1168

13. Oh DY, Talukdar S, Bae EJ, Imamura T, Morinaga H, Fan W, et al. GPR120 is an omega-3 fatty acid receptor mediating potent anti-inflammatory and insulinsensitizing effects. Cell (2010) 142(5):687-98. doi:10.1016/j.cell.2010.07.041

14. Fredriksson R, Hoglund PJ, Gloriam DE, Lagerstrom MC, Schioth HB. Seven evolutionarily conserved human rhodopsin $\mathrm{G}$ protein-coupled receptors lacking close relatives. FEBS Lett (2003) 554(3):381-8. doi:10.1016/S0014-5793(03) 01196-7

15. Burns RN, Moniri NH. Agonism with the omega-3 fatty acids alpha-linolenic acid and docosahexaenoic acid mediates phosphorylation of both the short and long isoforms of the human GPR120 receptor. Biochem Biophys Res Commun (2010) 396(4):1030-5. doi:10.1016/j.bbrc.2010.05.057

16. Watson SJ, Brown AJ, Holliday ND. Differential signaling by splice variants of the human free fatty acid receptor GPR120. Mol Pharmacol (2012) 81(5):631-42. doi:10.1124/mol.111.077388 
17. Moore K, Zhang Q, Murgolo N, Hosted T, Duffy R. Cloning, expression, and pharmacological characterization of the GPR120 free fatty acid receptor from cynomolgus monkey: comparison with human GPR120 splice variants. Comp Biochem Physiol B Biochem Mol Biol (2009) 154(4):419-26. doi:10.1016/j.cbpb. 2009.08.005

18. Gotoh C, Hong YH, Iga T, Hishikawa D, Suzuki Y, Song SH, et al. The regulation of adipogenesis through GPR120. Biochem Biophys Res Commun (2007) 354(2):591-7. doi:10.1016/j.bbrc.2007.01.028

19. Ichimura A, Hirasawa A, Poulain-Godefroy O, Bonnefond A, Hara T, Yengo L, et al. Dysfunction of lipid sensor GPR120 leads to obesity in both mouse and human. Nature (2012) 483(7389):350-4. doi:10.1038/nature10798

20. Tanaka T, Katsuma S, Adachi T, Koshimizu TA, Hirasawa A, Tsujimoto G. Free fatty acids induce cholecystokinin secretion through GPR120. Naunyn Schmiedebergs Arch Pharmacol (2008) 377(4-6):523-7. doi:10.1007/s00210007-0200-8

21. Tanaka T, Yano T, Adachi T, Koshimizu TA, Hirasawa A, Tsujimoto G. Cloning and characterization of the rat free fatty acid receptor GPR120: in vivo effect of the natural ligand on GLP-1 secretion and proliferation of pancreatic beta cells. Naunyn Schmiedebergs Arch Pharmacol (2008) 377(4-6):515-22. doi:10.1007/s00210-007-0250-y

22. Cornall LM, Mathai ML, Hryciw DH, McAinch AJ. Diet-induced obesity upregulates the abundance of GPR43 and GPR120 in a tissue specific manner. Cell Physiol Biochem (2011) 28(5):949-58. doi:10.1159/000335820

23. Cornall LM, Mathai ML, Hryciw DH, McAinch AJ. GPR120 agonism as a countermeasure against metabolic diseases. Drug Discov Today (2014) 19(5):670-9. doi:10.1016/j.drudis.2013.11.021

24. Takaesu G, Surabhi RM, Park KJ, Ninomiya-Tsuji J, Matsumoto K, Gaynor RB. TAK1 is critical for IkappaB kinase-mediated activation of the NF-kappaB pathway. J Mol Biol (2003) 326(1):105-15. doi:10.1016/S0022-2836(02)01404-3

25. Liu Y, Chen LY, Sokolowska M, Eberlein M, Alsaaty S, Martinez-Anton A, et al. The fish oil ingredient, docosahexaenoic acid, activates cytosolic phospholipase A via GPR120 receptor to produce prostaglandin E and plays an anti-inflammatory role in macrophages. Immunology (2014). doi:10.1111/imm. 12296

26. Kohout TA, Lefkowitz RJ. Regulation of G protein-coupled receptor kinases and arrestins during receptor desensitization. Mol Pharmacol (2003) 63(1):9-18. doi:10.1124/mol.63.1.9

27. Lefkowitz RJ, Shenoy SK. Transduction of receptor signals by beta-arrestins. Science (2005) 308(5721):512-7. doi:10.1126/science.1109237

28. Sanchez-Reyes OB, Romero-Avila MT, Castillo-Badillo JA, Takei Y, Hirasawa A, Tsujimoto $G$, et al. Free fatty acids and protein kinase $C$ activation induce GPR120 (free fatty acid receptor 4) phosphorylation. Eur J Pharmacol (2014) 723:368-74. doi:10.1016/j.ejphar.2013.11.003

29. Burns RN, Singh M, Senatorov IS, Moniri NH. Mechanisms of homologous and heterologous phosphorylation of FFA receptor 4 (GPR120): GRK6 and PKC mediate phosphorylation of $\operatorname{Thr}(3)(4)(7), \operatorname{Ser}(3)(5)(0)$, and $\operatorname{Ser}(3)(5)(7)$ in the C-terminal tail. Biochem Pharmacol (2014) 87(4):650-9. doi:10.1016/j. bcp. 2013.12 .016

30. Miyauchi S, Hirasawa A, Iga T, Liu N, Itsubo C, Sadakane K, et al. Distribution and regulation of protein expression of the free fatty acid receptor GPR120. Naunyn Schmiedebergs Arch Pharmacol (2009) 379(4):427-34. doi:10.1007/s00210-008-0390-8

31. Cartoni C, Yasumatsu K, Ohkuri T, Shigemura N, Yoshida R, Godinot N, et al. Taste preference for fatty acids is mediated by GPR40 and GPR120. J Neurosci (2010) 30(25):8376-82. doi:10.1523/JNEUROSCI.0496-10.2010

32. Suckow AT, Polidori D, Yan W, Chon S, Ma JY, Leonard J, et al. Alteration of the glucagon axis in GPR120 (FFAR4) knockout mice: a role for GPR120 in glucagon secretion. J Biol Chem (2014) 289(22):15751-63. doi:10.1074/jbc.M114.568683

33. Oh DY, Olefsky JM. Omega 3 fatty acids and GPR120. Cell Metab (2012) 15(5):564-5. doi:10.1016/j.cmet.2012.04.009

34. Cintra DE, Ropelle ER, Moraes JC, Pauli JR, Morari J, Souza CT, et al. Unsaturated fatty acids revert diet-induced hypothalamic inflammation in obesity. PLoS One (2012) 7(1):e30571. doi:10.1371/journal.pone.0030571

35. Wellhauser L, Belsham DD. Activation of the omega-3 fatty acid receptor GPR120 mediates anti-inflammatory actions in immortalized hypothalamic neurons. J Neuroinflammation (2014) 11(1):60. doi:10.1186/1742-2094-11-60

36. Nobili V, Carpino G, Alisi A, De Vito R, Franchitto A, Alpini G, et al. Role of docosahexaenoic acid treatment in improving liver histology in pediatric nonalcoholic fatty liver disease. PLoS One (2014) 9(2):e88005. doi:10.1371/ journal.pone.0088005

37. Raptis DA, Limani P, Jang JH, Ungethum U, Tschuor C, Graf R, et al. GPR120 on Kupffer cells mediates hepatoprotective effects of omega3-fatty acids. J Hepatol (2014) 60(3):625-32. doi:10.1016/j.jhep.2013.11.006

38. Chai W, Dong Z, Wang N, Wang W, Tao L, Cao W, et al. Glucagon-like peptide 1 recruits microvasculature and increases glucose use in muscle via a nitric oxidedependent mechanism. Diabetes (2012) 61(4):888-96. doi:10.2337/db11-1073

39. Zhao T, Parikh P, Bhashyam S, Bolukoglu H, Poornima I, Shen YT, et al. Direct effects of glucagon-like peptide-1 on myocardial contractility and glucose uptake in normal and postischemic isolated rat hearts. J Pharmacol Exp Ther (2006) 317(3):1106-13. doi:10.1124/jpet.106.100982

40. Baron AD, Brechtel G, Wallace P, Edelman SV. Rates and tissue sites of noninsulin- and insulin-mediated glucose uptake in humans. Am J Physiol (1988) 255(6 Pt 1):E769-74.

41. Zurlo F, Larson K, Bogardus C, Ravussin E. Skeletal muscle metabolism is a major determinant of resting energy expenditure. J Clin Invest (1990) 86(5):1423-7. doi:10.1172/JCI114857

42. Small CJ, Bloom SR. Gut hormones and the control of appetite. Trends Endocrinol Metab (2004) 15(6):259-63. doi:10.1016/j.tem.2004.06.002

43. Mendieta-Zeron H, Lopez M, Dieguez C. Gastrointestinal peptides controlling body weight homeostasis. Gen Comp Endocrinol (2008) 155(3):481-95. doi:10.1016/j.ygcen.2007.11.009

44. Flint A, Raben A, Astrup A, Holst JJ. Glucagon-like peptide 1 promotes satiety and suppresses energy intake in humans. J Clin Invest (1998) 101(3):515-20. doi:10.1172/JCI990

45. Liu Q, Anderson C, Broyde A, Polizzi C, Fernandez R, Baron A, et al. Glucagonlike peptide- 1 and the exenatide analogue AC3174 improve cardiac function, cardiac remodeling, and survival in rats with chronic heart failure. Cardiovasc Diabetol (2010) 9:76. doi:10.1186/1475-2840-9-76

46. van den Hoek AM, Heijboer AC, Corssmit EP, Voshol PJ, Romijn JA, Havekes LM, et al. PYY3-36 reinforces insulin action on glucose disposal in mice fed a high-fat diet. Diabetes (2004) 53(8):1949-52. doi:10.2337/diabetes.53.8.1949

47. van den Hoek AM, Heijboer AC, Voshol PJ, Havekes LM, Romijn JA, Corssmit EP, et al. Chronic PYY3-36 treatment promotes fat oxidation and ameliorates insulin resistance in C57BL6 mice. Am J Physiol Endocrinol Metab (2007) 292(1):E238-45. doi:10.1152/ajpendo.00239.2006

48. Gong Z, Yoshimura M, Aizawa S, Kurotani R, Zigman JM, Sakai T, et al. G protein-coupled receptor 120 signaling regulates ghrelin secretion in vivo and in vitro. Am J Physiol Endocrinol Metab (2014) 306(1):E28-35. doi:10.1152/ ajpendo.00306.2013

49. Engelstoft MS, Park WM, Sakata I, Kristensen LV, Husted AS, Osborne-Lawrence $\mathrm{S}$, et al. Seven transmembrane $\mathrm{G}$ protein-coupled receptor repertoire of gastric ghrelin cells. Mol Metab (2013) 2(4):376-92. doi:10.1016/j.molmet.2013.08.006

50. Little TJ, Horowitz M, Feinle-Bisset C. Role of cholecystokinin in appetite control and body weight regulation. Obes Rev (2005) 6(4):297-306. doi:10.1111/j. 1467-789X.2005.00212.x

51. Stone VM, Dhayal S, Brocklehurst KJ, Lenaghan C, Sorhede Winzell M, Hammar M, et al. GPR120 (FFAR4) is preferentially expressed in pancreatic delta cells and regulates somatostatin secretion from murine islets of Langerhans. Diabetologia (2014) 57(6):1182-91. doi:10.1007/s00125-014-3213-0

52. Kebede MA, Alquier T, Latour MG, Poitout V. Lipid receptors and islet function: therapeutic implications? Diabetes Obes Metab (2009) 11(Suppl 4):10-20. doi:10.1111/j.1463-1326.2009.01114.x

53. Morgan NG, Dhayal S. G-protein coupled receptors mediating long chain fatty acid signalling in the pancreatic beta-cell. Biochem Pharmacol (2009) 78(12):1419-27. doi:10.1016/j.bcp.2009.07.020

54. Taneera J, Lang S, Sharma A, Fadista J, Zhou Y, Ahlqvist E, et al. A systems genetics approach identifies genes and pathways for type 2 diabetes in human islets. Cell Metab (2012) 16(1):122-34. doi:10.1016/j.cmet.2012.06.006

55. Matsumura S, Eguchi A, Mizushige T, Kitabayashi N, Tsuzuki S, Inoue K, et al. Colocalization of GPR120 with phospholipase-Cbeta2 and alpha-gustducin in the taste bud cells in mice. Neurosci Lett (2009) 450(2):186-90. doi:10.1016/j. neulet.2008.11.056

56. Martin C, Passilly-Degrace P, Chevrot M, Ancel D, Sparks SM, Drucker DJ, et al. Lipid-mediated release of GLP-1 by mouse taste buds from circumvallate papillae: putative involvement of GPR120 and impact on taste sensitivity. J Lipid Res (2012) 53(11):2256-65. doi:10.1194/jlr.M025874 
57. Ozdener MH, Subramaniam S, Sundaresan S, Sery O, Hashimoto T, Asakawa Y, et al. CD36- and GPR120-mediated $\mathrm{Ca}(2+)$ signaling in human taste bud cells mediates differential responses to fatty acids and is altered in obese mice. Gastroenterology (2014) 146(4):995-1005. doi:10.1053/j.gastro.2014.01.006

58. Nasser J. Taste, food intake and obesity. Obes Rev (2001) 2(4):213-8. doi:10. 1046/j.1467-789X.2001.00039.x

59. Suzuki T, Igari S, Hirasawa A, Hata M, Ishiguro M, Fujieda $H$, et al. Identification of $\mathrm{G}$ protein-coupled receptor 120-selective agonists derived from PPARgamma agonists. J Med Chem (2008) 51(23):7640-4. doi:10.1021/jm800970b

60. Briscoe CP, Peat AJ, McKeown SC, Corbett DF, Goetz AS, Littleton TR, et al. Pharmacological regulation of insulin secretion in MIN6 cells through the fatty acid receptor GPR40: identification of agonist and antagonist small molecules. Br J Pharmacol (2006) 148(5):619-28. doi:10.1038/sj.bjp.0706770

61. Hara T, Hirasawa A, Sun Q, Sadakane K, Itsubo C, Iga T, et al. Novel selective ligands for free fatty acid receptors GPR120 and GPR40. Naunyn Schmiedebergs Arch Pharmacol (2009) 380(3):247-55. doi:10.1007/s00210-009-0425-9

62. Sun Q, Hirasawa A, Hara T, Kimura I, Adachi T, Awaji T, et al. Structure-activity relationships of GPR120 agonists based on a docking simulation. Mol Pharmacol (2010) 78(5):804-10. doi:10.1124/mol.110.066324

63. Shimpukade B, Hudson BD, Hovgaard CK, Milligan G, Ulven T. Discovery of a potent and selective GPR120 agonist. J Med Chem (2012) 55(9):4511-5. doi:10.1021/jm300215x
64. Hudson BD, Shimpukade B, Mackenzie AE, Butcher AJ, Pediani JD, Christiansen E, et al. The pharmacology of TUG-891, a potent and selective agonist of the free fatty acid receptor 4 (FFA4/GPR120), demonstrates both potential opportunity and possible challenges to therapeutic agonism. Mol Pharmacol (2013) 84(5):710-25. doi:10.1124/mol.113.087783

Conflict of Interest Statement: The authors declare that the research was conducted in the absence of any commercial or financial relationships that could be construed as a potential conflict of interest.

Received: 29 May 2014; paper pending published: 17 June 2014; accepted: 02 July 2014; published online: 16 July 2014.

Citation: Oh DY and Walenta E (2014) Omega-3 fatty acids and FFAR4. Front. Endocrinol. 5:115. doi: 10.3389/fendo.2014.00115

This article was submitted to Diabetes, a section of the journal Frontiers in Endocrinology.

Copyright (C) 2014 Oh and Walenta. This is an open-access article distributed under the terms of the Creative Commons Attribution License (CC BY). The use, distribution or reproduction in other forums is permitted, provided the original author(s) or licensor are credited and that the original publication in this journal is cited, in accordance with accepted academic practice. No use, distribution or reproduction is permitted which does not comply with these terms. 